\title{
Retraction Note to: Adaptive neuro-fuzzy evaluation of wind farm power production as function of wind speed and direction
}

\author{
Dalibor Petković ${ }^{1} \cdot$ Shahaboddin Shamshirband ${ }^{2,3} \cdot$ Nor Badrul Anuar ${ }^{2} \cdot$ Sareh Naji $^{4} \cdot$ Miss Laiha Mat Kiah $^{2}$. \\ Abdullah Gani ${ }^{2}$
}

Published online: 29 May 2019

(c) Springer-Verlag GmbH Germany, part of Springer Nature 2019

\section{Retraction Note to: Stoch Environ Res Risk Assess (2015) 29:793-802 https://doi.org/10.1007/s00477-014-0901-8}

The Editor-in-Chief has retracted this article (Petković et al. 2015a) because validity of the content of this article cannot be verified. This article showed evidence of substantial text overlap [most notably with the articles cited (Basser et al. 2014a, b; Petković et al. 2014a, b, 2015b, c; Erdem and Shi 2011)], peer review and authorship manipulation. The authors do not agree to this retraction.

\section{References}

Basser H, Shamshirband S, Petković D et al (2014a) Adaptive neurofuzzy prediction of the optimum parameters of protective spur dike. Nat Hazards 73:1439. https://doi.org/10.1007/s11069-014$1145-0$

Basser H, Shamshirband S, Karami H et al (2014b) Adaptive neurofuzzy selection of the optimal parameters of protective spur dike. Nat Hazards 73:1393. https://doi.org/10.1007/s11069-014-1140-5

Erdem E, Shi J (2011) ARMA based approaches for forecasting the tuple of wind speed and direction. Appl Energy

The original article can be found online at https://doi.org/10.1007/s00477-014-0901-8.

Dalibor Petković

dalibortc@gmail.com

1 Department for Mechatronics and Control, Faculty of Mechanical Engineering, University of Niš, Aleksandra Medvedeva 14, 18000 Nis, Serbia

2 Department of Computer System and Technology, Faculty of Computer Science and Information Technology, University of Malaya, 50603 Kuala Lumpur, Malaysia

3 Department of Computer Science, Islamic Azad University, Chalous Branch, 46615-397 Chalous, Iran

4 Department of Civil Engineering, Faculty of Engineering, 50603 Kuala Lumpur, Malaysia
88(4):1405-1414. https://doi.org/10.1016/j.apenergy.2010.10. 031

Petković D, Shamshirband S, Anuar NB et al (2014a) An appraisal of wind speed distribution prediction by soft computing methodologies: a comparative study. Energy Convers Manag 84:133-139. https://doi.org/10.1016/j.enconman.2014.04.010

Petković D, Ab Hamid SH, Ćojbašić Ž et al (2014b) Adapting project management method and ANFIS strategy for variables selection and analyzing wind turbine wake effect. Nat Hazards 74:463. https://doi.org/10.1007/s11069-014-1189-1

Petković D, Shamshirband S, Anuar NB et al (2015a) Adaptive neurofuzzy evaluation of wind farm power production as function of wind speed and direction. Stoch Environ Res Risk Assess 29:793. https://doi.org/10.1007/s00477-014-0901-8

Petković D, Ćojbašić Ž, Nikolić V et al (2015b) Adaptive neuro-fuzzy maximal power extraction of wind turbine with continuously variable transmission. Energy 64:868-874. https://doi.org/10. 1016/j.energy.2013.10.094

Petković D, Shamshirband S, Iqbal J et al (2015c) Adaptive neurofuzzy prediction of grasping object weight for passively compliant gripper. Appl Soft Comput 22:424-431. https://doi. org/10.1016/j.asoc.2014.04.037

Publisher's Note Springer Nature remains neutral with regard to jurisdictional claims in published maps and institutional affiliations. 